Original Research Article

\title{
Analgesic use and potential hearing loss: a pharmacovigilance study
}

\author{
Meena K. N. ${ }^{1}$, Dwajani S. ${ }^{1,2 *}$, Nagaraj T. M. ${ }^{3}$, Roshan Kumar B. N. ${ }^{4}$, Rajiv S. ${ }^{1}$
}

\author{
${ }^{1}$ Department of Pharmacology, \\ ${ }^{2}$ Central Research Lab, \\ ${ }^{3}$ Department of ENT, \\ ${ }^{4}$ Department of Orthopaedics, \\ RRMCH, Bangalore, Karnataka, \\ India
}

\section{Received: 20 July 2017 \\ Revised: 08 August 2017 \\ Accepted: 22 August 2017 \\ *Correspondence to: \\ Dr. Dwajani S., \\ Email: dwajani@gmail.com}

Copyright: () the author(s), publisher and licensee Medip Academy. This is an openaccess article distributed under the terms of the Creative Commons Attribution NonCommercial License, which permits unrestricted noncommercial use, distribution, and reproduction in any medium, provided the original work is properly cited.

\begin{abstract}
Background: Hearing loss is the most common sensory deficit in humans today. In India, as per WHO there are approximately 63 million people, who are suffering from significant auditory impairment and estimated prevalence at $6.3 \%$ in Indian population. The objective of the study was to determine the potential hearing loss in patients on analgesics.

Methods: Prospective, observational study examined the association between analgesic use and potential hearing loss in 30 patients receiving NSAIDS. Data was collected using specialized designed case record form. The clinical signs like onset of tinnitus, appearance of another sound that didn't exist before, sinus infection or a respiratory illness, development of vertigo or spinning sensation were looked for. Audiometry test was advised for all the patients receiving analgesics.

Results: Total of 30 patients were included in the study. Male predominance was noted Maximum patients were in the age group between 35-45 years (33.33\%). The socioeconomic status was analyzed using revised kuppuswamy scale. $30 \%$ $(n=09)$ of patients were in lower class. Majority of the patients were reported with road traffic accidents $(n=19 ; 63.33 \%)$ and received analgesics for more than 2 weeks. Patients received different combination of NSAIDs among which aceclofenac was most commonly prescribed. 11 (36.66\%) patients had hearing loss received either diclofenac or aceclofenac for more than 25 days.

Conclusions: Regular usage of NSAIDS may increase the risk of hearing loss and the impact could be larger on younger individuals. Hence, extra precaution to be taken while prescribing NSAIDS.
\end{abstract}

Keywords: Analgesics, Hearing loss, Non steroidal anti-inflammatory drugs, Pharmacovigilance

\section{INTRODUCTION}

Hearing loss is the most common sensory deficit in humans today. In India, as per WHO there are approximately 63 million people, who are suffering from significant auditory impairment and estimated prevalence at $6.3 \%$ in Indian population. As per NSSO survey, currently there are 291 persons per one lakh population who are suffering from severe to profound hearing loss (NSSO, 2001). With such a large number of hearing impaired in young Indians, it amounts to a severe loss of productivity, both physical and economic and adversely affecting work productivity, social connectivity, lowering quality of life. An even larger percentage of our population suffers from milder degrees of hearing loss.
Use of analgesics is common and is associated with increased risk of hearing loss. However, the relation has not been examined prospectively. Hearing loss is a common and disabling chronic condition. Although the prevalence is higher in men, one-third of women in their 50 s and almost two-thirds of women in their 60s suffer from hearing loss. ${ }^{1}$ Even mild hearing loss impairs communication and social interaction, adversely affecting work productivity, social connectivity, and quality of life. ${ }^{2,3}$ The World Health Organization ranks adult-onset hearing loss as the sixth most common disease burden in high-income countries. ${ }^{4}$ Hearing loss represents an important public health concern, yet there are limited data on potentially modifiable risk factors for adult hearing loss. Ibuprofen, acetaminophen, and aspirin are the 3 most 
commonly used medications. ${ }^{5}$ Potential ototoxicity (damage to the cochlea or auditory nerve) due to high doses of salicylates and nonsteroidal anti-inflammatory drugs (NSAIDs) has been previously described and may result from several mechanisms, such as impaired outer hair cell function, inhibition of prostaglandin-forming cyclooxygenase, and reduced cochlear blood flow. ${ }^{6-11}$ Potential ototoxicity from Acetaminophen may be due to the depletion of glutathione, which has been shown to protect the cochlea from noise-induced damage. ${ }^{11-14}$

The cause of acquired hearing loss is multifactorial. In a given individual, potential contributors to hearing loss include processes associated with aging, noise exposure, inherited genetic factors and systemic conditions. The relative contribution of some risk factors, such as analgesic use, to hearing loss may be larger in younger persons, before the cumulative effects of aging, noise, and other factors have substantially affected hearing. Hence the objective of the study was to determine the potential hearing loss in patients on analgesics in order to become aware of this potential not so well known side effect of ototoxicity.

\section{METHODS}

This study was conducted in accordance with ICH-GCP Guidelines. This study is being carried out in department of pharmacology, ENT and Orthopaedics in collaboration central research laboratory at tertiary care hospital, Bangalore, India. The data was collected from Mar 2017 to June 2017 for a period of 4 months.

Total of 30 patients were recruited in the study as a pilot run. Regular users of analgesics, i.e. 1 or more per week for a period of 2 weeks or more, attending a tertiary care hospital, of both sexes between 18-60 years of age were included in the study. Patients diagnosed with hearing loss, those exposed to chronic noise pollution like factory workers, patients on ototoxic drugs like aminoglycosides or furosemide, patients with known case of hypertension and diabetes were excluded from the study.

Data was collected using a specialized designed case record form. Demographic, clinical and treatment details like dose, frequency, and duration of the treatment were collected. The proper details of the drug being used, its duration and dose were recorded. The clinical signs to look for were onset of tinnitus (disturbing noises) in one or both ears, worsening of existing tinnitus or the appearance of another sound that didn't exist before, fullness or pressure in your ears that cannot be attributed to other causes, such as sinus infection or a respiratory illness, onset of hearing loss in the unaffected ear, the development of vertigo or spinning sensation usually aggravated. Audiometry test was advised for all the patients receiving analgesics. Audiometry instrument used was Elkon eda 3n3 multi diagnostic audiometer with serial number: em $2 \mathrm{k} 5322$. The details of the patients, obtained data and the observations was known only to the researcher, hence confidentiality was maintained.

All the data were entered into Microsoft excel sheet before analysis. The data was analyzed using descriptive statistics. Quantitative data was expressed as mean and standard deviation, while qualitative data was expressed as percentage and frequency distribution.

\section{RESULTS}

Total of 30 patients were included in the study. Male predominance was noted in the study 17 [56.66\%], while 13 (43.33) were female. Maximum patients were in the age group between $35-45$ years $(33.33 \%)$ followed by patients between 26-35 years (26.66\%). The distribution among different age groups is been represented in Figure 1.

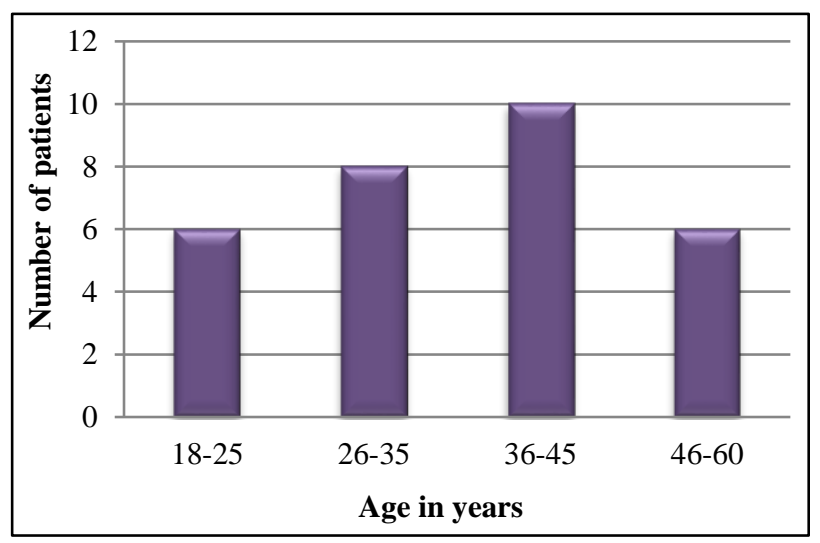

Figure 1: Age wise distribution of study population.

The socioeconomic status of these 30 patients was analyzed using revised kuppuswamy scale. 30\% $(n=09)$ of patients were in lower class, $36.66 \%(n=11)$ were in upper lower class while $33.33 \%(n=10)$ of patients were in middle class.

With regards to the diagnosis, majority of the patients were reported with road traffic accidents $(n=19 ; 63.33 \%)$ and received analgesics for more than 2 weeks. Rest of the patients were diagnosed with intervertebral disc prolapse (IVDP), lower back pain, cervical spondylitis and chronic synovitis receiving analgesics (Table 1).

Table 1: Disease pattern of patients receiving analgesics.

\begin{tabular}{|lll|}
\hline No & $\begin{array}{l}\text { Diagnosis of the } \\
\text { problem }\end{array}$ & $\begin{array}{l}\text { Total number of } \\
\text { patients }(\mathbf{n = 3 0})\end{array}$ \\
\hline 1 & Road traffic accidents & $19(63.33)$ \\
\hline 2 & $\begin{array}{l}\text { Intervertebral disc } \\
\text { prolapse (IVDP) }\end{array}$ & $05(16.66)$ \\
\hline 3 & lower back pain & $04(13.33)$ \\
\hline 4 & cervical spondylitis & $01(3.33)$ \\
\hline 5 & chronic synovitis & $01(3.33)$ \\
\hline
\end{tabular}


With respect to the treatment data, we included patients who received analgesics and noticed that majority of patients received NSAIDs. Patients received different combination of NSAIDs (Table 2) among which aceclofenac was most commonly prescribed followed by diclofenac. All the patients received NSAIDs twice daily for more than 1 month. When audiometry tests were performed on these 30 patients, $11(36.66 \%)$ patients had moderate hearing loss while remaining 19 patients $(63.33 \%)$ had normal hearing. Among 11 patients who had hearing loss received either diclofenac or aceclofenac for more than 25 days. Table 2: Total number of patients received
medications with or without combination.

\begin{tabular}{|ll|}
\hline $\begin{array}{l}\text { Medications used with /without } \\
\text { combination }\end{array}$ & $\begin{array}{l}\text { Total number of } \\
\text { patients }(\mathbf{n}=\mathbf{3 0})\end{array}$ \\
\hline Aceclofenac + Rabeprazole & 17 \\
\hline $\begin{array}{l}\text { Diclofenac + Paracetamol + } \\
\text { Serattiopeptidase }\end{array}$ & 08 \\
\hline Aceclofenac + Paracetamol & 03 \\
\hline Aceclofenac & 02 \\
\hline
\end{tabular}

\section{DISCUSSION}

There is always a high level of curiosity about the possible effects of medications on regular use. Analgesics are those drugs which give temporary relief to a variety of pain causing factors and are also one of the most widely used group of drugs. Although these analgesics are safe and effective when taken as directed and for short-term use, they may cause serious problems for people who take too much and use them frequently. One of the most serious side effects that has been observed during the usage of these analgesics is hearing loss, also known as ototoxicity.

Regular analgesic use was associated with an increased risk of hearing loss and was greatest among younger men, particularly those below age 60 years. The risk of hearing loss increased with longer duration of analgesic use for both NSAIDs and acetaminophen. The ototoxic effects of high-dose salicylates, reversible hearing loss and tinnitus, are well documented. ${ }^{6}$ In animal models, salicylate administration results in abnormal outer hair cell function and decreased cochlear blood flow. ${ }^{6}$ Salicylates induce biochemical and electrophysiological changes that alter membrane conductance of outer hair cells and vasoconstriction in auditory microvasculature, possibly mediated by antiprostaglandin activity. ${ }^{14}$

High doses of NSAIDs also have been reported to be ototoxic in animal studies and in human case reports. ${ }^{15}$ Similar to salicylates, NSAIDs inhibit cyclooxygenase and decrease prostaglandin activity, potentially reducing cochlear blood flow. ${ }^{6}$

The prevalence of hearing loss increases with age. ${ }^{16}$ After age 60 years, hearing thresholds worsen on average by 1
$\mathrm{dB}$ per year, and the rate of decline might be even greater in men aged 48-59 years. ${ }^{17,18}$ The magnitude of the relation between regular analgesic use and hearing loss was greatest in men younger than age 60 years. Possibly, the relative contribution of regular analgesic use to hearing loss may be greater in younger individuals before the cumulative effects of age and other factors have accrued. A similar impact of age on the relative contribution of diabetes to hearing loss was seen by Bainbridge and his colleagues. $^{19}$ The impact of regular use of multiple analgesics can be additive. This raises the possibility that the different classes of analgesics may impair auditory function through different mechanisms. ${ }^{20}$

Our study has limitations as this is a pilot study with small sample size. No covariates like smoking and alcohol were excluded from the study. However, additional studies with larger sample size are needed to examine these associations in women, men, and other racial groups. Regular use of analgesics, specifically aspirin, NSAIDs, and acetaminophen, might increase the risk of adult hearing loss, particularly in younger individuals. Given the high prevalence of regular analgesic use and health and social implications of hearing impairment, this represents an important public health issue. Study is being continued among larger population with strict inclusion and exclusion criteria.

\section{CONCLUSION}

Regular use of NSAIDS or acetaminophen may increase the risk of hearing loss and the impact could be larger on younger individuals.

\section{Funding: No funding sources}

Conflict of interest: None declared

Ethical approval: The study was approved by the Institutional Ethics Committee

\section{REFERENCES}

1. Agrawal Y, Platz EA, Niparko JK. Prevalence of hearing loss and differences by demographic characteristics among US adults: data from the National Health and Nutrition Examination Survey, 1999-2004. Arch Intern Med. 2008;168(14):1522-30.

2. Olusanya BO, Ruben RJ, Parving A. Reducing the burden of communication disorders in the developing world: an opportunity for the Millennium Development Project. JAMA. 2006;296(4):441-44.

3. Gates GA, Cobb JL, Linn RT, Rees T, Wolf PA, D'agostino RB. Central auditory dysfunction, cognitive dysfunction, and dementia in older people. Archives of Otolaryngology-Head \& Neck Surgery. 1996 Feb 1;122(2):161-7.

4. Lopez AD, Mathers CD, Ezzati M, Jamison DT, Murray CJ. Global and regional burden of disease and risk factors, 2001: systematic analysis of population health data. The Lancet. 2006 Jun 2;367(9524):174757. 
5. Kaufman DW, Kelly JP, Rosenberg L, Anderson TE, Mitchell AA. Recent patterns of medication use in the ambulatory adult population of the United States: the Slone survey. Jama. 2016;287(3):337-44.

6. Jung TT, Rhee CK, Lee CS, Park YS, Choi DC. Ototoxicity of salicylate, nonsteroidal antiinflammatory drugs, and quinine. Otolaryngologic clinics of North America. 1993 Oct;26(5):791-810.

7. McKinnon BJ, Lassen LF. Naproxen-associated sudden sensorineural hearing loss. Mil Med. 1998;163(11):792-3.

8. Cazals Y. Auditory sensori-neural alterationsinduced by salicylate. Prog Neurobiol. 2000;62(6):583-631.

9. Boettcher FA, Salvi RJ. Salicylate ototoxicity: Review and synthesis. Am J Otolaryngol. 1991;12(1):33-47.

10. Brien JA. Ototoxicity associated with salicylates: a brief review. Drug Saf. 1993;9(2):143-8.

11. Moldèus $P$, Rahimtula A. Metabolism of paracetamol to a glutathione conjugate catalyzed by prostaglandin synthetase. Biochem Biophys Res Commun. 1980;96(1):469-75.

12. Yamasoba T, Harris C, Shoji F, Lee RJ, Nuttall AL, Miller JM. Influence of intense sound exposure on glutathione synthesis in the cochlea. Brain research. 1998 Aug 31;804(1):72-8.

13. Yamasoba T, Nuttall AL, Harris C, Raphael Y, Miller JM. Role of glutathione in protection against noiseinduced hearing loss. Brain research. 1998 Feb 16;784(1):82-90.

14. Stypulkowski PH. Mechanisms of salicylate ototoxicity. Hear Res.1990;46:113-45.
15. McFadden D, Plattsmier HS, Pasanen EG. Temporary hearing loss induced by combinations of intense sounds and nonsteroidal anti-inflammatory drugs. Am J Otolaryngol. 1984;5:235-41.

16. Cruickshanks KJ, Wiley TL, Tweed TS, Klein BE, Klein R, Mares-Perlman JA, et al. Prevalence of hearing loss in older adults in Beaver Dam, Wisconsin: The epidemiology of hearing loss study. American journal of epidemiology. 1998 Nov 1;148(9):879-86.

17. Lee FS, Matthews LJ, Dubno JR, Mills JH. Longitudinal study of pure-tone thresholds in older persons. Ear Hear. 2005;26:1-11.

18. Wiley TL, Chappell R, Carmichael L, Nondahl DM, Cruickshanks KJ. Changes in hearing thresholds over 10 years in older adults. Journal of the American Academy of Audiology. 2008 Apr 1;19(4):281-92.

19. Bainbridge KE, Hoffman HJ, Cowie CC. Diabetes and hearing impairment in the United States: audiometric evidence from the National Health and Nutrition Examination Survey, 1999 to 2004. Ann Intern Med. 2008;149:1-10.

20. Curhan SG, Eavey R, Shargorodsky J, Curhan GC. Analgesic Use and the Risk of Hearing Loss in Men. The American J of Medicine. 2010;123:231-7.

Cite this article as: Meena KN, Dwajani S, Nagaraj TM, Kumar RBN, Rajiv S. Analgesic use and potential hearing loss: a pharmacovigilance study. Int J Basic Clin Pharmacol 2017;6:2380-3. 